\title{
An overview of 5G Technology and Challenges
}

\author{
Rajinder Singh \\ Department of Computer Science and Applications \\ PUSSGRC Hoshiarpur (Pb.) \\ Email: rajinderid@gmail.com
}

\begin{abstract}
Main objective of this paper is to make a comprehensive study of 5G technology.5G Networks will provide many benefits over the currently available 4G LTE networks. Main goal of 5G technology is to meet the demands of high user data rates. $5 \mathrm{G}$ wireless technology is supposed to provide more capabilities than the previous wireless technology. It will provide high data rates, high reliability and low latency. Main components of 5G networks will be high frequency bands, device to device communication and multiple antennas for transmission. This paper highlights all these components. It also highlights various different challenges which are faced by $5 \mathrm{G}$ technology. Some of these components are already used in the previous high speed networks and some of them are still under development phase.
\end{abstract}

Keywords-Small Cell; MIMO; Beamforming;

\section{INTRODUCTION}

5G means fifth generation. 5G network are currently under development and they are expected to hit the market in 2020. It is the next step to replace the currently available 4G LTE technology. 5G technology is the next mobile internet technology. Main features of $5 \mathrm{G}$ network are faster speed and reliable connections. It will provide higher data rates and much network efficiency. 5G network will help in boosting the IoT technology. Average download speed of $5 \mathrm{G}$ is expected to be around $1 \mathrm{Gbps}$. It uses radio waves to transmit and receive user's data [1]

\section{MAIN FEATURES OF 5G NETWORK}

Main features of $5 \mathrm{G}$ technologies are:

According to IMT-2020 specifications 5G network is expected to have the following features.

\subsection{Very high speed}

$5 \mathrm{G}$ network is expected to deliver more speed as compared to $4 \mathrm{G}$ networks. User data rate is expected to $1 \mathrm{Gbit} / \mathrm{s}$. Peak download capacity for $5 \mathrm{G}$ network is expected to 20Gbits/s. Now a high definition movie can be downloaded within few second [2][11].

\subsection{More capacity}

5G network will have increased bandwidth. It is supposed to provide 1,000 times more capacity as compared to currently available $4 \mathrm{G}$ network.

\subsection{Reduced Latency}

It will stop the transmission delay between the two communicating devices. Latency means time taken by the sender to send a message to a receiver. In case of
5G network it is expected to $1 \mathrm{~ms}$. It will help in handling multiplayer mobile game, self driving cars, and robots [2][11].

\subsection{Provide larger bandwidth}

For supporting increased throughput new spectrum frequency bands are allocated. It will utilize the existing LTE spectrum $(600 \mathrm{MHz}$ to $6 \mathrm{GHz})$ as well as millimeter wave bands $(24-86 \mathrm{GHz})[1]$.

\subsection{Lower battery consumption devices}

Earlier high speed network stress the devices and result is poor battery life. But $5 \mathrm{G}$ network promise to offer better battery life. 5G networks offer best possible connection to the connecting devices, increasing battery life [3].

\subsection{Uninterrupted and consistent connectivity}

$5 \mathrm{G}$ signals are more reliable than the previous mobile network radio signals. $5 \mathrm{G}$ technology is a combination of various advanced technology which will be very helpful for providing users uninterrupted and consistent connectivity.

\subsection{Allow access to parallel multiple services}

One of the disadvantages of the earlier high speed networks is due to the less bandwidth multiple applications are not supported simultaneously. But 5G network will support multiple applications simultaneously [3][4].

\subsection{Remote place access}

Currently wireless network development in the remote area is still very poor. In these areas transmission 


\section{Available online at www.ijrat.org}

speed of the data is very less [12]. 5G will use massive MIMO technology to improve the speed [5].

All these features of $5 \mathrm{G}$ technology are shown in the table 1 given below.

Table 1. 5G Features and Benefits

\section{Main Features of 5G and their benefits}

\begin{tabular}{|ll|l|}
\hline S.N. & Features & Benefits to Users \\
\hline $\mathbf{1}$ & High Speed & $\begin{array}{l}\text { It will handle many users } \\
\text { within same area, many } \\
\text { devices and their traffic } \\
\text { demands. }\end{array}$ \\
\hline $\mathbf{2}$ & Low Latency & $\begin{array}{l}\text { Handle Time bound } \\
\text { Traffic more easily and in } \\
\text { accurate way. }\end{array}$ \\
\hline $\mathbf{3}$ & $\begin{array}{l}\text { High Speed } \\
\text { Mobility }\end{array}$ & $\begin{array}{l}\text { Supporting users which } \\
\text { are moving with a very } \\
\text { high speed. }\end{array}$ \\
\hline $\mathbf{4}$ & $\begin{array}{l}\text { New Radio } \\
\text { Spectrum }\end{array}$ & $\begin{array}{l}\text { It will utilize the } \\
\text { millimeter waves and } \\
\text { radio carrier aggregation }\end{array}$ \\
\hline $\mathbf{5}$ & Massive & $\begin{array}{l}\text { Increased throughput } \\
\text { within a sector }\end{array}$ \\
\hline $\mathbf{6}$ & MIMO & $\begin{array}{l}\text { Increase in data capacity, } \\
\text { longer battery life, low } \\
\text { latency rates }\end{array}$ \\
\hline
\end{tabular}

\section{5G Techniques}

Many new 5G techniques are developed for inclusion

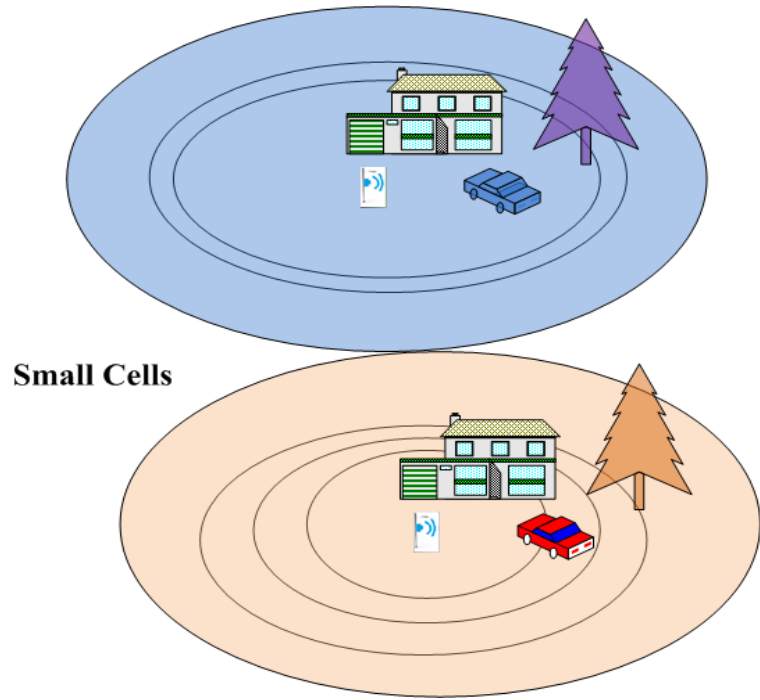

Figure 1 Small Cells in the 5G Network. All these new techniques will help $5 \mathrm{G}$ networks for achieving high efficiency. These new techniques will also help $5 \mathrm{G}$ networks for providing flexible and dynamic services. Main techniques which are included in 5G are given below:

\subsection{Small Cell}

As the number of users in the network increase, demand for the higher data rates also increase. One solution for this problem is to decrease the size of the cell and deploying many small cells. These are the low power transmission systems which cover the small geographical area. They can be placed on the wall or on the lamp post for supporting indoor or outdoor applications. These cells are further divided into three major categories i) pico ii) micro and iii) femato [10][17].

Figure 1 shows the small cells are used for covering small areas.

\subsection{Massive MIMO}

MIMO technology is the core component of $5 \mathrm{G}$ Network. This technology allows transmission and receiving of multiple signals simultaneously. MIMO technology use two or four antenna but massive MIMO uses a high number of antenna arrays. Main benefits of using massive MIMO are capacity of the wireless connection will be multiplied without requiring the more spectrum. It will help users to provide better data rates and reliability of the link [11].

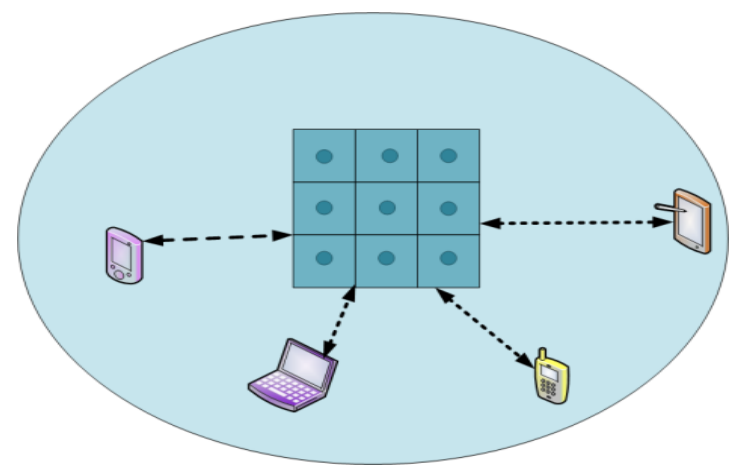

Figure 2 Multiple Antennas used in MIMO

\subsection{Carrier Aggregation}

Users nowadays demanding more mobile data from the network providers, therefore mobile carriers and manufacturers must increase the capacity and should offer this data with faster speed. But they have already utilized the existing Radio Frequency Spectrum. One solution for this problem is Carrier Aggregation. With the help of Carrier aggregation multiple channels are combined together to increase the performance of the network. This technique also allows the user faster 


\section{Available online at www.ijrat.org}

downloading and uploading. Carrier Aggregation is already used in 4G LTE advance networks [13].

\subsection{Device to device communication}

It is a technology that allows user's device to communicate with the other device without the need of base station or access point. These can be cell phones or vehicle. One main application of D2D

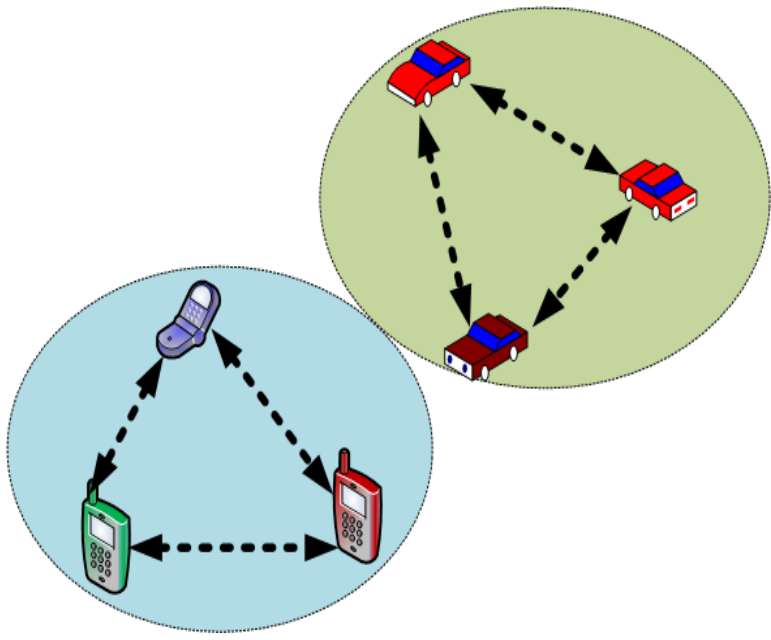

Figure 3 D2D Communication

communication technology is to provide the users local connectivity for safety purposes in case of damage to radio infrastructure [6][7].

\subsection{Radio Network Access}

5 GNR technology will be used by $5 \mathrm{G}$ mobile network. It will utilize sub-6GHz frequency and mmWave frequency bands [8].

\section{5G technology depending factors}

Many new technologies are being developed to be included in 5G standard. These new technologies will help the $5 \mathrm{G}$ networks to achieve the desired requirements [5]. Some main technologies are discussed below:

\subsection{Millimeter waves}

Spectrum range for $4 \mathrm{G}$ is from $2 \mathrm{GHz}$ to $6 \mathrm{GHz}$. But nowadays users which are using $4 \mathrm{G}$ technologies are increasing data by day. Therefore all these users are using the same spectrum. So congestion in the network is also increasing. Transmission speed is also reducing between the two communicating devices. To overcome these problems there is need to use the higher spectrum. Millimeter waves uses spectrum within the range of $30-300 \mathrm{GHz}$, which can be used to increase the speed between the two communicating devices.

\subsection{Small Cells:}

Main drawbacks of millimeter waves are that these waves cannot pass through buildings, trees, and mountains. These waves have very less wavelength. Therefore instead of using a single antenna many smaller base stations are used.

\subsection{Massive MIMO}

MIMO means multiple input and multiple output. This technology is used in $4 \mathrm{G}$. But in case of $5 \mathrm{G}$ this technology is increased 4 more times.

\subsection{Beamforming}

Since $5 \mathrm{G}$ technology is using Massive MIMO so there is interference between the transmitted signals. In order to decrease the Interference a method beam forming is used. Beamforming means shaping of the radio signals and confining in such a way that these are focused on a particular area. Confining the radio signals avoids the unnecessary noise interference and the target area receives the maximum signal quality [9].

\section{5G Technological Challenges}

Main Challenges for 5G with respect to technology are given below:

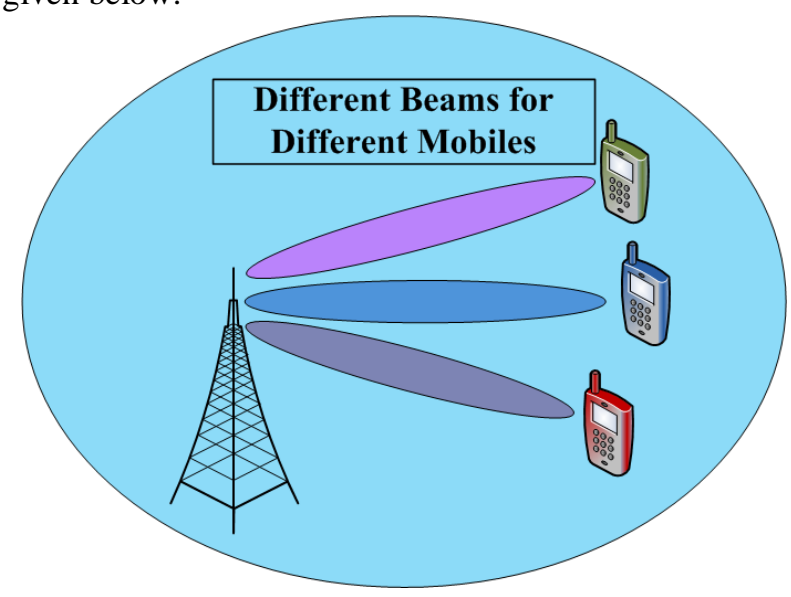

Figure 4 Beamforming 


\section{E-ISSN: 2321-9637 \\ Available online at www.ijrat.org}

\subsection{Interference}

It is the major issue that needs to be solved.

Due to the difference between the size of small cell and macro cell there will be interference problem [14].

\subsection{Device to device communication}

It is the new concept where one mobile device is communicating with the other device, without using the base station signal. This concept is very important in case of various emergency situations where there is poor signal or network is absent. Therefore there is need of complex transmission protocols to implement D2D communication. If the number of communicating devices increases within the same cell then there will be congestion problem [15].

\subsection{Hardware for handling the new frequency bands}

Current LTE devices operate below $3.5 \mathrm{GHz}$ range. But in case of $5 \mathrm{G}$ unlicensed spectrum below $6 \mathrm{~Hz}$ will be utilized. But the design of the hardware for handling millimeter waves is very complex. It will increase the device complexity [15].

\subsection{Massive MIMO Technology:}

Massive MIMO technology will be used in 5G. MIMO means multiple inputs and multiple outputs. So complex algorithm will be needed to implement this technology. Moreover this will also increase the complexity of user device and base stations [15].

\subsection{Security and Privacy}

Security and privacy is the major factor for any wireless transmission system. $5 \mathrm{G}$ network must ensure security and privacy of end users data and applications [15].

\subsection{IOT}

$4 \mathrm{G}$ is already deployed in many countries but it will not support many new applications which will come in the next 5 or 10 years. Many applications related to IOT will not be supported by $4 \mathrm{G}$. $5 \mathrm{G}$ technology will increase the data rates, and will reduce the end to end latency. These features are important for applications related to IOT. Another issue related to $4 \mathrm{G}$ is that in case of $4 \mathrm{G}$ there are different types of short range networks. e.g. RIFD, Bluetooth, UWB. But these existing small network technologies will not support IOT applications. So there is a need of unified network and $5 \mathrm{G}$ can provide solution for this [16].

\subsection{Small Cells}

5G technology has to deal with the issues such as higher band width, low latency, high data rates and reliability. To address these problems $5 \mathrm{G}$ technology has to use small cell concept. Small cell cover small geographical area. Small cell use short range and low power transmission systems. These small cells support all the features of the basic conventional base station. These systems can handle high data rates for the individual users. These small systems can be fixed on the wall for managing indoor applications or on the small tower or on the lamp post for handling outdoor applications. Backhaul connections can be made by using microwave or wired or using fiber connections.

Problems with the small cell are that these signals will have lower penetration power. So coverage area will be very small. High power transmitter will be needed to cover the area [17].

\section{CONCLUSION}

In this paper new techniques and technologies which will be used by $5 \mathrm{G}$ Network are explained. One main objective of $5 \mathrm{G}$ is to help building smart cities. It will support high speed interactive multimedia, voice and other services over $5 \mathrm{G}$ networks. It will provide high capacity without decreasing the transmission speed. Now many users can be added to the network without decreasing the transmission speed. This paper also highlights research problem related to these technologies.

\section{REFERENCES}

[1] https://en.wikipedia.org/wiki/5G

[2] https://www.guidingtech.com/5g-wirelesstechnology-features/

[3] https://www.guidingtech.com/5g-wirelesstechnology-features/

[4] https://www.rfpage.com/how-5g-technologyworks/

[5] https://www.electronicsnotes.com/articles/connectivity/5g-mobilewireless-cellular/technology-basics.php

[6] https://spectrum.ieee.org/computing/networks/app lications-of-devicetodevice-communication-in$5 \mathrm{~g}$-networks

[7] https://www.ericsson.com/en/blog/2014/7/d2dcommunications---what-part-will-it-play-in-5g

[8] https://en.wikipedia.org/wiki/5G_NR

[9] https://www.fitce.gr/everything-need-know-5g/

[10] Gupta, Akhil, and Rakesh Kumar Jha. "A survey of 5G network: Architecture and emerging technologies." IEEE access 3 (2015): 1206-1232.

[11] E. G. Larsson, F. Tufvesson, O. Edfors, and T. L. Marzetta, "Massive MIMO for next generation wireless systems," IEEE Commun. Mag., vol. 52, no. 2, pp. 186-195, Feb. 2014. 
International Journal of Research in Advent Technology, Vol.7, No.2, February 2019 E-ISSN: 2321-9637

\section{Available online at www.ijrat.org}

[12] http://theinstitute.ieee.org/ieee-

roundup/blogs/blog/how-5g-could-bring-internetaccess-to-remote-areas

[13] https://www.networkworld.com/article/3238885/5 g-and-the-need-for-speed.html

[14] https://www.tutorialspoint.com/5g/5g_challenges. htm

[15] https://www.rfpage.com/what-are-the-challengesin-5g-technology/

[16] https://spectrum.ieee.org/techtalk/computing/networks/5g-taking-stock

[17] https://www.rfpage.com/what-are-small-cells-in5g-technology/ 